\title{
Penurunan Temperatur Kondensor pada Sistem Pendingin Central Processing Unit (CPU) Berbasis Cascade Straight Heat Pipe
}

\author{
Imanuel Adam Tnunay ${ }^{1)}$, Wayan Nata Septiadi ${ }^{2)^{*}}$, I Nyoman Budiarsa ${ }^{2)}$ \\ ${ }^{1)}$ Program Studi Magister Teknik Mesin,Fakultas Teknik, Universitas Udayana \\ Kampus Sudirman, Bali 80232 \\ Email: Imanueltn92@gmail.com \\ 2) Jurusan Teknik Mesin Teknik Mesin, Fakultas Teknik, Universitas Udayana, \\ Kampus Bukit Jimbaran, Bali 80362 \\ Email: wayan.nata@gmail.com, budiarsa nyoman@yahoo.co.id \\ doi: $\quad$ https://doi.org/10.24843/METTEK.2018.v04.i02.p05
}

\begin{abstract}
Abstrak
Dalam menunjang kehidupan manusia, teknologi terus mengalami perkembangan. Hal ini terlihat dalam dalam berbagai bidang teknologi seperti elektronik, pembangkit listrik, robotik, permesinan dan lain-lain. Perkembangan CPU terus mengarah kepada dimensi yang semakin kecil namun kinerja meningkat sehingga membutuhkan sistem pendingin yang memiliki kemampuan yang cukup tinggi untuk mampu menjaga kinerja dan umur CPU. Belakangan ini teknologi Heat Pipe mulai banyak digunakan karena memiliki kemampuan kinerja sangat baik dalam mentransfer panas. Kemampuan yang baik dalam menstransfer panas berdampak pada temperatur buang di bagian kondensor yang juga tinggi mencapai $50^{\circ} \mathrm{C}-60^{\circ} \mathrm{C}$. Hal ini akan berdampak kurang baik terhadap komponen lain yang berada di sekitar CPU. Berdasarkan hal tersebut peneliti mencoba menerapkan metode cascade straight heat pipe, guna menurunkan temperatur yang di buang pada bagian kondensor, akan tetapi kinerja pengangkutan panas pada bagian CPU tetap optimal. Hasil penelitian menunjukan bahwa Sistem Pendingin CPU CHP kondensor tunggal mampu menurunkan temperatur kondensor pada kondisi idle sebesar 14,94 ${ }^{0} \mathrm{Cdan}$ pada kondisi maksimal sebesar $21,12{ }^{\circ} \mathrm{C}$. Cascade Double kondensormampu menurunkan temperatur kondensor pada kondisi idle sebesar $17,12{ }^{0} \mathrm{C}$, dan pada kondisi maksimal sebesar $24,16{ }^{\circ} \mathrm{C}$. Hasilnya lebih rendah bila dibandingkan dengan sistem pendingin NC.Persentasi penurunan temperatur kondensor beban idle dengan menggunakan sistem pendingin CPU CHP terhadap temperatur kondensor Non Cascade adalah dengan menggunakan $C H P$ tunggal kondensor sebesar $28 \%$ dan $C H P$ Doublesebesar $32 \%$. Pada bebanmaksimal adalah dengan menggunakan CHP tunggal kondensor sebesar $35 \%$ dan dengan CHP Double Kondensor sebesar $40 \%$.
\end{abstract}

Kata kunci: Kondensor,Cascade Straight Heat Pipe, CPU, fluks kalor.

\begin{abstract}
In supporting human life, technology continues to develop. This looks in various fields of technology such as electronics, power generation, robotics, machinery and others other. Development CPU continues to lead to ever smaller dimensions but increased performance so requires a cooling system that has a high enough ability to be able to maintain the performance and age of the CPU. Lately Heat Pipe technology began to be widely used because it has excellent performance capabilities in heat transfer. Good capability in heat transfer has an impact on the exhaust temperature in the condenser section which also reaches a high of $50{ }^{\circ} \mathrm{C}-60{ }^{\circ} \mathrm{C}$. This will have an adverse effect on
\end{abstract}

*Penulis korespondensi, HP: 081916356509

Email: wayan.nata@gmail.com 
other components around the CPU. Based on this, the researchers tried to apply the cascade straight heat pipe method, in order to reduce the exhaust temperature in the condenser section, but the heat transport performance in the CPU section remained optimal. The results showed that the CPU Cooling System of a single HP condenser was able to reduce the temperature of the condenser at idle conditions by $14.94{ }^{\circ}$ Cand at maximum conditions of $21.12{ }^{\circ} \mathrm{C}$. Cascade Double Condenser able to reduce the temperature of the condenser at idle at $17.12{ }^{\circ} \mathrm{C}$ and the maximum condition of $24.16^{\circ} \mathrm{C}$. The result was lower when compared with the Cooling system NC. The percentage decrease in temperature of the idle load condenser by using the CPU CHP cooling system to the temperature of the Cascade Non Ccondenser is to use CHP single condenser of $28 \%$ and CHP Double $32 \%$. On load the maximum is to use a single CHP condenser of $35 \%$ and with CHP Double Condenser at $40 \%$.

Keyword: Condensor, Cascade Straight Heat Pipe, CPU, heat fluks.

\section{PENDAHULUAN}

Perkembangan teknologi terus mengalami perkembangan seiring dengan semakin kompleksnya kebutuhan manusia. Perkembangan teknologi meliputi banyak bidang, seperti elektronik, komputer, bidang transportasi, komunikasi dan berbagai bidang lainnya.[1]. Untuk mampu menunjang kehidupan dan membantu aktifitas manusia teknologi mulai mengarah ke sistem smart teknologi dimana teknologi yang diciptakan memiliki kemampuan yang cukup untuk membantu kegiatan manusia disamping itu teknologi juga diharapkan memiliki ukuran yang sekecil mungkin sehingga sangat mudah untuk digunakan secara mobile[2].Central Processing Unit (CPU) adalah suatu perangkan lunak atau Hardware dalam sistem komputerisasi yang memiliki tugas pentingdalam mengelola data maupun menjalankan aplikasi-aplikasi yang dapat mempermudah proses pekerjaan manusia, kebutuhan ini akan terus mendorong berkembangannya teknologi mengenai CPU baik dalam segi dimensi, kinerja maupun efisiensi [3].

Fluks kalor yang yang dihasilkan oleh proses kerja CPU sangat tinggi sehingga membutuhkan suatu sistem yang mampu bekerja ekstra dan efektif untuk mengatur fluks kalor tersebut,dengan adanya sistem pendingin ini, sangat diharapkan untuk dapat bekerja mengurangi serta memenajemen fluks kalor dari CPU agar bisa berkurang bahkan dihilangkan dari CPU tersebut [4].Pada umumnya banyak alat-alat dan perangkat elektronik yang berpotensi menghasilkan fluks kalor melebihi $100 \mathrm{~W} / \mathrm{cm}^{2}$, permalahan fluks kalor ini perlu mendapat kajian khusus sehingga dapat dimanajemen dengan baik[5]. Penggunaan dan Pemanfaatan media perpindahan panas konvensional seperti udara, air, etilenaglikol kurang mampu dalam mengatasi fluks kalor tersebut sehingga CPU sangat membutuhkan media perpindahan panas dengan kemampuan memindahkan atau mengangkut fluks kalor yang tinggi dan baik[3].

Heat Pipe (Pipa Kalor) adalah teknlogi pengantar kalor atau penukar kalor,biasanya terbuat dari pipa tembaga ataupun logam lainnya. Di bagian dinding dalamnya berisi material berpori pada serta juga disi fluida kerja sebagai media pengangkut dan penyalur kalor atau panas serta juga untuk memompa cairan kembali ke bagian evaporator, material lapisan berpori ini disebut dengan wick heat pipe.[6] Penggunaan Heat Pipe dapat bekerja apabila terdapat sumber panas yang terpisah dengan daerah pendingin atau kondensor. Prinsip kerja Heat Pipe adalah menyerap panaspada sumber panas melalui permukaan evaporator, pada temperatur tertentu fluida akan menguap menuju kondensor melalui daerah adiabatik, setelah sampai di daerah kondensor akan terkondensasimenjadi cairan dan mengalir kembali ke sisi panas (evaporator) dari heat pipe dan proses ini akan terus-menerus terjadi selama heat pipe digunakan sebagai sistem atau media transfer dan penghantar panas atau kalor[7]. 
Kemampuan kerja yang baik dari Heat Pipe juga memiliki dampak pada temperatur buangan di bagian kondensor yang masihtinggi mencapai $50^{\circ} \mathrm{C}-60^{\circ} \mathrm{C}$ [8]. Panas yang dilepaskan pada bagian kondensor tersebut dapat merusak alat-alat serta komponen elektronik yang ada di sekitar sistem tersebut, maka dengan demikian sangat diperlukanlah sistem pendingin yang handal dan mampu menyerap kalor pada processor CPU secara optimal.

\section{METODE}

\subsection{Rancangan Cascade Straight Heat Pipe}

Dalam proses penelitian ini menggunaan metode experimental yang tersusun dalam beberapa tahapan penyelesaian, pada bagian pertama adalah mempersiapakan desain alat berupa heat pipe berukuran lebar $8 \mathrm{~mm}$, tebal $4 \mathrm{~mm}$ dan panjang $100 \mathrm{~mm}$. Ukuran desain dibuat dengan memepertimbangkan batas kerja heat pipe serta luas area sekitar perangkat CPU dan processor. Gambar 1 merupakan rancangan cascade straight heat pipe, dimana Heat Pipe tingkat pertama difungsikan sebagai evaporator yang berfungsi sebagai bagian yang menyerap kalor dari procesor CPU. Pada bagian ujung dari salah satu sisi heat pipe bagian pertama dilengkapi dengan plat kontak termal yang terbuat dari tembaga dengan dimensi $40 \mathrm{~mm}$ x $40 \mathrm{~mm}$ dan Heat Pipe tingkat kedua dilengkapi dengan sirip-sirip.
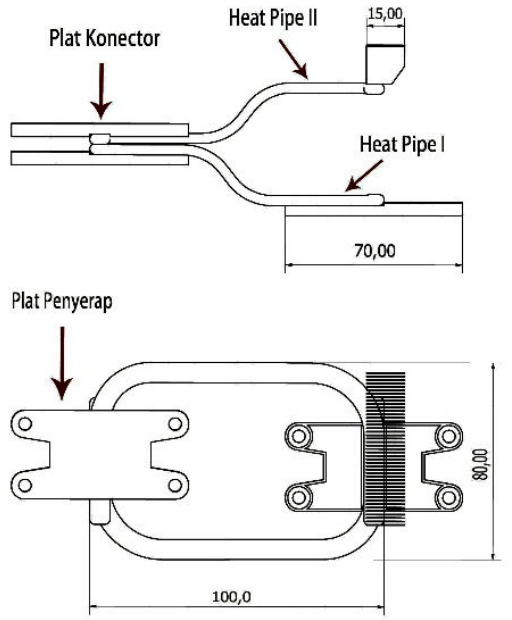
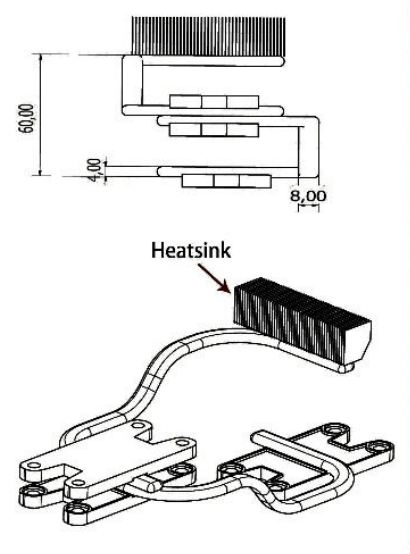

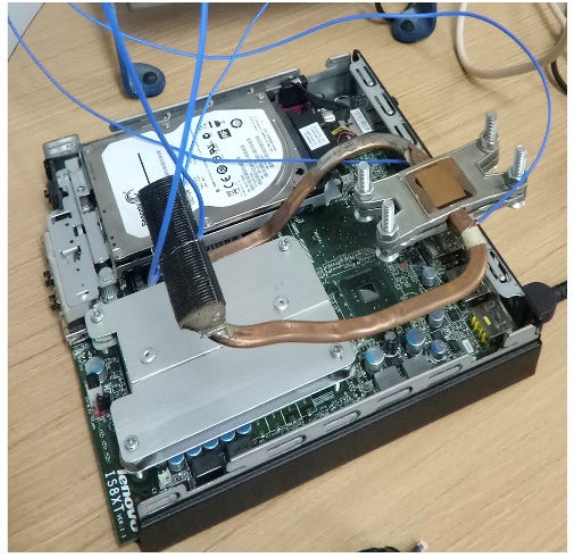

Gambar 1. Rancangan Cascade Straight Heat Pipe [9]

\subsection{Skematik Pengujian}

Gambar 2 merupakan skematik pengujian cascade straight heat pipe yang difungsikan sebagai sistem pendingin CPU. Pengujian dilakukan pada CPU Core i5 2,90 GHzdengan pembebanan pada kondisi tanpa pembebanan sebesar 10 Watt dan kondisi pembebanan maksimal 48 Watt. 5buah thermocouple tipe-K diletakkan pada beberapa titik pada desain berbentuk cascade kondensor tunggal dan 8 buahthermocouple pada Doublle Kondensor. Termokopel diletakan pada permukaan processor, bagian evaporator pada masing-masing heat pipe, dan bagian kondensor. Temperatur yang terukur pada termokopel oleh data aquisisi NIcDAQ 9174 dan NI 9213 di transfer ke sistem komputer yang akan diolah pada software Labview. Pengujian dilakukan dengan pengoperasian CPU sampai dengan kondisi steady-state dimana temperatur CPU dan kondensor tidak mengalami peningkatan temperatur atau sudah memberikan kondisi temperatur yang stabil. Pada kondisi ini dilakukan kontrol terhadap temperatur CPU yakni $\leq 80^{\circ} \mathrm{C}$. Apabila kondisi temperatur CPU belum berada pada kondisi di bawah $80^{\circ} \mathrm{C}$, maka pengujian pada kondisi tersebut dilakukan pengulangan dan pengecekan 
kembali pada sistem pemasangan pendingin cascade straight heat pipe.

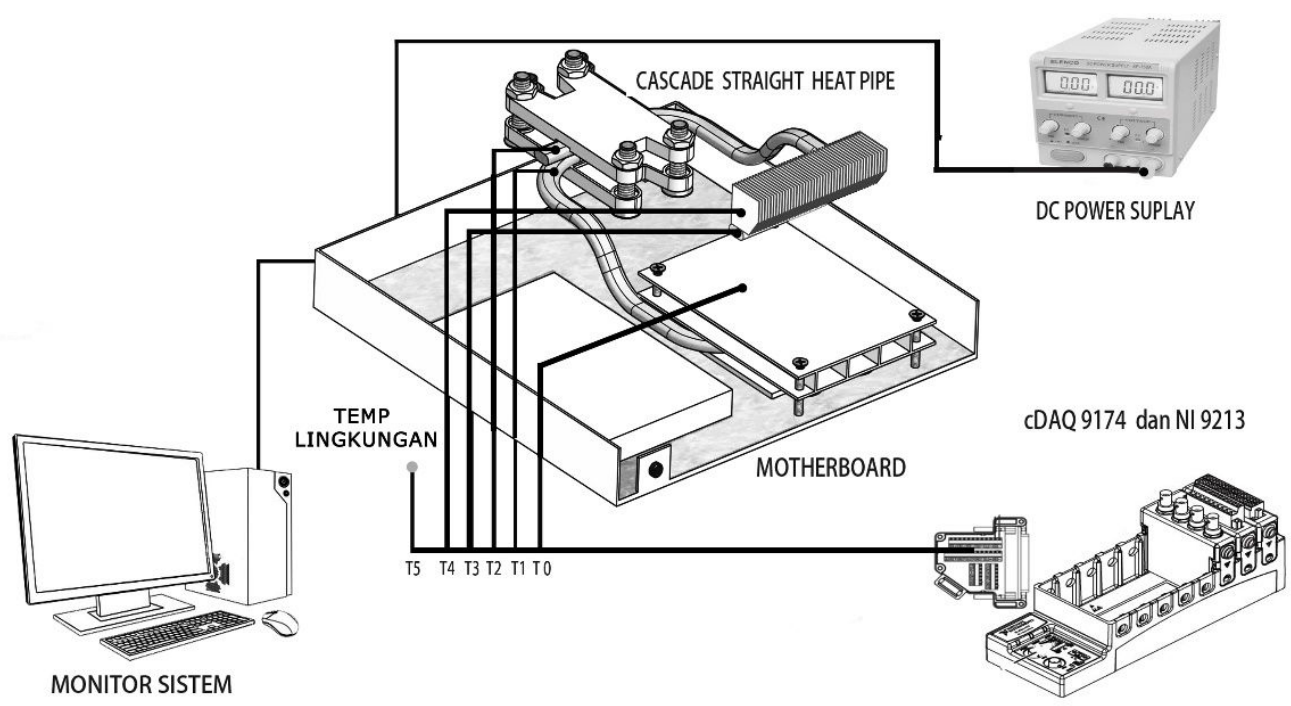

Gambar 2. Skematik pengujian

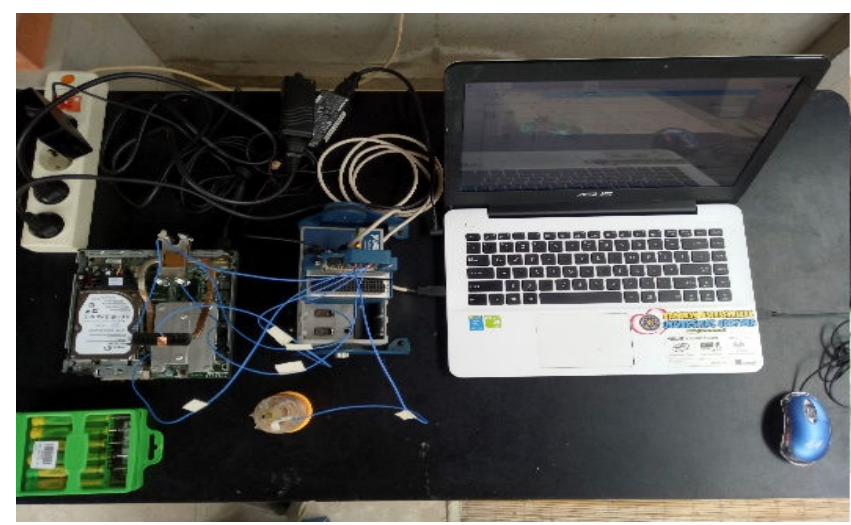

Gambar 3. Proses Pengambilan Data

\section{HASIL DAN PEMBAHASAN}

Distribusi temperatur kondensor sistem pendindinginNon Cascade, Cascade tunggal kondensor dan Cascade Double Kondensor pada Kondisi Idle 10 Watt dan maksimal 48 Watt ditunjukan pada gambar 4. Pembebanan idle 10 Watt menunjukkan temperatur kondensor Non Cascade mencapai 53,32 ${ }^{\circ} \mathrm{C}$, sedangkan dengan menggunakan sistem cascade menunjukkan temperatur Cascade tunggal kondensor mencapai $38,38^{\circ} \mathrm{C}$, dan Cascade Double Kondensor mencapai $36,21^{\circ} \mathrm{C}$. Pada pemberian beban maksimal 48 Watt menunjukkan temperatur kondensor Non Cascade mencapai $60,85^{\circ} \mathrm{C}$, sedangkan dengan menggunakan sistem Cascade menunjukan temperatur Cascade tunggal kondensor mencapai $39,73^{\circ} \mathrm{C}$, dan Cascade Double Kondensor mencapai $36,69^{0} \mathrm{C}$, proses ini terjadi mulai dari waktu 0 detik sampai keaadaan steady yaitu pada kisaran waktu 800 detik.

Pada grafik menunjukan kemampuan kinerja kerja yang baik dari sistem pendingin menggunakan Cascade Heat Pipe, dimana pada sistem pendingin CPUmenggunakan Cascade Heat mampu menurunkan temperatur keluaran di bagian kondensor baik pada posisi pembebanan idle maupun pembebanan maksimal. Sistem pendingin cascade tersebut bekerja sesuia dengan prinsip kerjanya sehingga panas pada processor dapat diserap dan disalurkan ke 
bagian kondensor buangan pada melalui proses suatu penguapan dan kondensasi. Prinsip ini akan terus terjadi selama sistem Pendingin tersebut digunakan.

Pada proses kerja sistem pendingin ini menunjukan bahwa temperatur akan naik ketika pada pemberian beban maksimal, hal ini ditunjukan dengan perbedaan grafik pada beban idle dan maksimal. Dari grafik ini juga dapat dilihat bahwa sistem Cascade Heat Pipe mampu menurunkan temperatur kondensor dibawah dari $40{ }^{0} \mathrm{C}$ lebih rendah dari sistem pendingin Non Cascade.

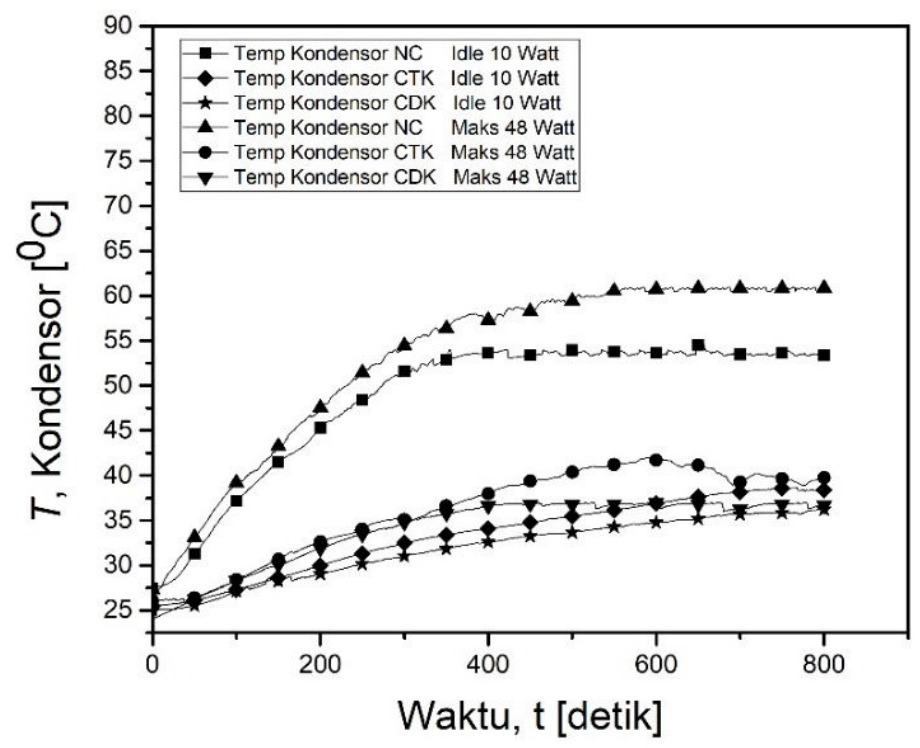

Gambar 4. Distribusi temperatur pada bagian kondensor Cascade Straight Heat Pipe

Pada tabel 1 dibawah ini menunjukan data temperatur operational kondensor sistem pendingin CPU berbasis Non Cascade (NC), Cascade Tunggal Kondensor (CTK), dan Cascade Double Kondensor (CDK) pada saat mencapai temperatur steady pada detik ke 800, dimana data tersebut menunjukan nilai penurunan temperatur kondensor dengan menggunakan sistem Cascade Heat Pipe terhadap Non Cascade dengan pembebanan Idle 10 Watt dan pembebanan maksimal 48 Watt.

Tabel 1. Data Temperatur Operational Kondensor Sistem Pendingin CPU

\begin{tabular}{lcccc}
\hline Daya (Watt) & Waktu detik (t) & $\begin{array}{c}\text { T Kondensor } \\
\text { NC }\end{array}$ & $\begin{array}{c}\text { T Kondensor } \\
\text { CTK }\end{array}$ & $\begin{array}{c}\text { T Kondensor } \\
\text { CDK }\end{array}$ \\
\hline Idle 10 Watt & 800 & 53,32 & 38,38 & 36,21 \\
\hline Maks 48 Watt & 800 & 60,85 & 39,73 & 36,69 \\
\hline
\end{tabular}

Dari analisa grafik diatas, maka dijabarkan lagi dalam bentuk diagram unuk menganalisa seberapa besar nilai penurunan temperatur operasional kondensor dari sistem Cascade Heat Pipe menggunakan Cascade Tunggal Kondensor (CTK), dan Cascade Double Kondensor (CDK) terhadap sistem pendingin Non Cascade (NC). Pada gambar 5 menunjukan penurunan temperatur kondensor pada pemberian beban idle 10 Watt, dari diagram tersebut terlihat besaran penurunan temperatur kondensor dengan menggunakan sistem pengindin CPU Cascade Heat Pipe berada dibawah $40{ }^{0} \mathrm{C}$. pada sistem tersebut menunjukan Cascade Tunggal Kondensor mampu menurunkan temperatur kondensor sampai $38,38^{\circ} \mathrm{Cdan}$ untuk Cascade Double Kondensor menurunkan sampai $36,21^{\circ} \mathrm{C}$, dari data ini dapat dihitung besar nilai penurunan temperatur pada pembebanan idle 10 Watt terhadap sistem Non Cascade, 
dimana Sistem Cascade Tunggal Kondensor dapat menurunkan sebesar $14,94{ }^{0} \mathrm{C}$ dan Cascade Double Kondensor sebesar $21,12{ }^{\circ} \mathrm{C}$.

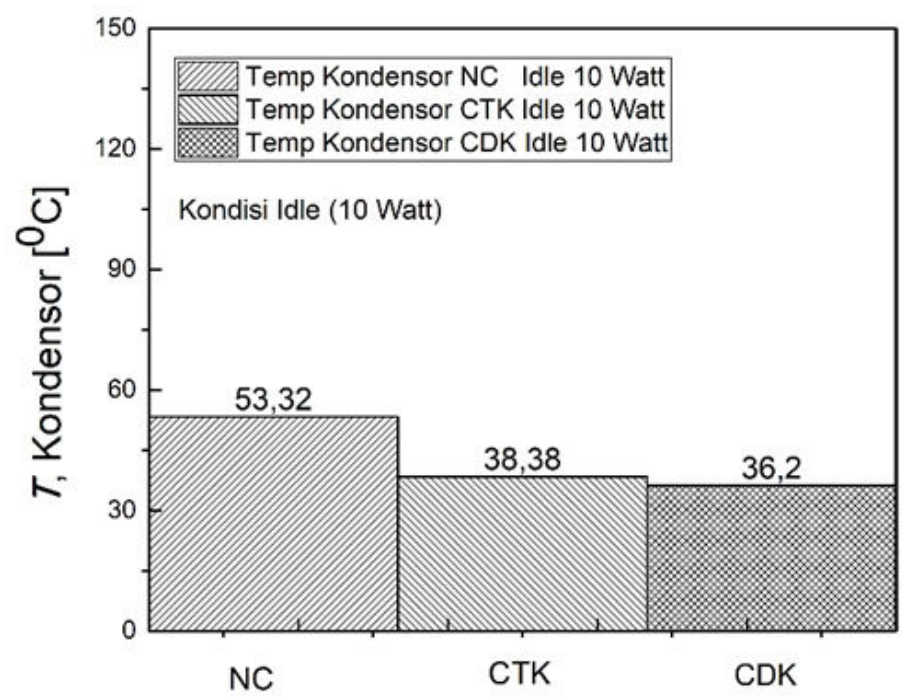

Gambar 5.Perbandingan temperatur kondensor sistem pendingin CPU cascade straight heat pipe pada pembebanan 10 Watt.

Pada gambar 6 menunjukan penurunan temperatur kondensor pada pemberian beban maksimal 48 Watt, dari diagram tersebut terlihat besaran penurunan temperatur kondensor dengan menggunakan sistem pengindin CPU Cascade Heat Pipe berada dibawah $40{ }^{\circ} \mathrm{C}$. pada sistem tersebut menunjukan Cascade Tunggal Kondensor mampu bekerja untuk menurunkan temperatur kondensor sampai $39,73^{\circ} \mathrm{Cdan}$ untuk Cascade Double Kondensor menurunkan sampai $36,69^{\circ} \mathrm{C}$, dari data ini dapat dihitung besar nilai penurunan temperatur pada pembebanan maksimal 48 Watt terhadap sistem Non Cascade, dimana SistemCascade Tunggal Kondensor dapat menurunkan sebesar $17,12{ }^{\circ} \mathrm{C}$ dan Cascade Double Kondensor sebesar $24,16{ }^{0} \mathrm{C}$.

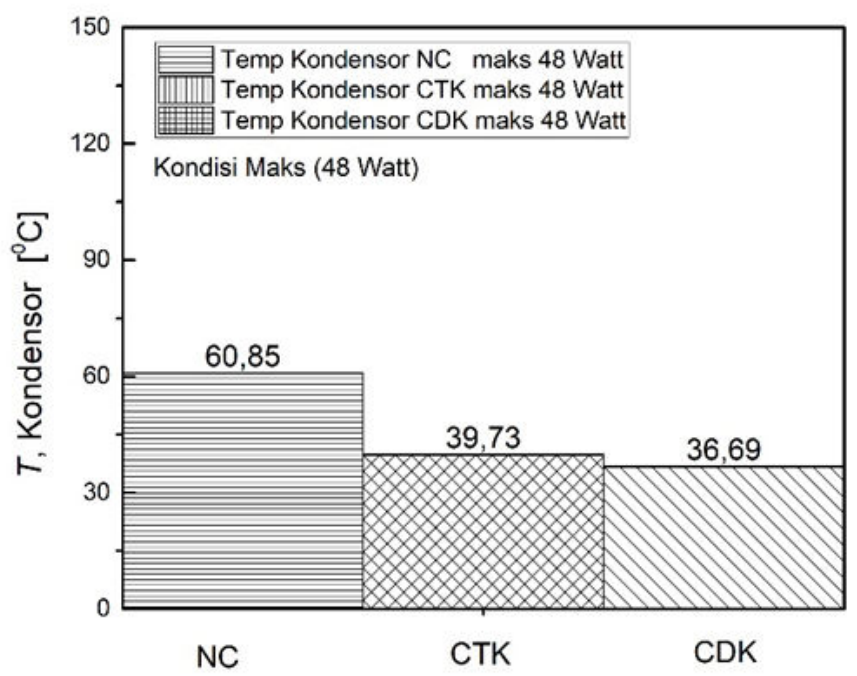

Gambar 6.Perbandingan temperatur kondensor sism pendingin CPU cascade stright heat pipe pada pembebanan 48 Watt. 


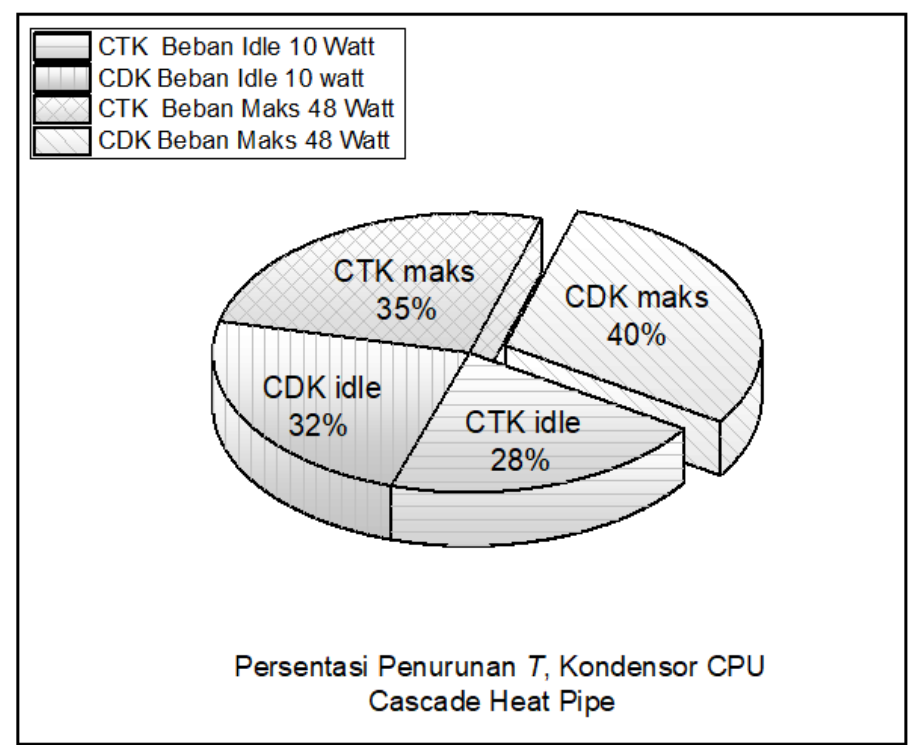

Gambar 7. Diagram Persentasi Penurunan Temperatur Kondensor CPU Cascade Heat Pipe Terhadan Non Cascade

Perhitungan persentasi juga dilakukan untuk dapat mengetahui seberapa besar persentasi penurunan temperatur kondensor ketika menggunakan sistem Cascade Heat Pipe dalam penerapan sebagai sistem pendingin $\mathrm{CPU}$, oleh karena itu pada gambar 7 menujukan persentasi penurunan temperatur kondensor Cascade Heat Pipe jika dibandingkan dengan sistem pendingin tanpa menggunakan Cascade. persentasi penurunan temperatur menggunakan sistem Cascade Tunggal Kondensor (CTK) pada pemberian beban idle 10 Watt adalah sebesar $28 \%$ dan pada pemberian beban maksimal 48 Watt adalah sebesar 35\%. Sedangkan persentasi penurunan temperatur menggunakan sistem pendingin Cascade Double Kondensor (CDK) pada pemberian beban idle 10 Watt adalah sebesar $32 \%$ dan pada pemberian beban maksimal 48 Watt adalah sebesar 40\%. Penggunaan dan pemanfaatan sistem Cascade Heat Pipesangat memberikan manfaat terhadap upaya untuk mengurangi masalah pada komponen dan alat-alat yang ada disekitar CPU pada sistem komputer.

\section{SIMPULAN}

Dari hasil penelitian yang telah dilakukan maka dapat diambil kesimpulan bahwa untuk memanejemen fluks kalor atau overheating pada CPU dapat menerapkan sistem pendingin Cascade Heat Pipe dimana hasil penelitian menunjukan kemampuan penggunaan sistem Cascade Tunggal Kondensor dapat bekerja menurunkan temperatur kondensorsebesar 14,94 ${ }^{0}$ Cpada kondisi beban idle dan sebesar $17,12{ }^{0} \mathrm{Cpada}$ kondisi beban maksimal, dengan persentasi penurunan sebesar $28 \%$ pada kondisi idle dan 35\% pada kondisi maksimal. Hal ini juga dibuktikan pada penggunaan sistem pendingin Cascade Double Kondensor (CDK) dapat menurunkan temperatur kondensorsebesar $21,12{ }^{\circ} \mathrm{C}$ pada kondisi idle dan sebesar $24,16{ }^{0} \mathrm{C}$ pada kondisi beban maksimal dengan persentasi penurunan sebesar $32 \%$ pada kondisi idle dan $40 \%$ pada kondisi beban maksimal, dari data ini menyimpulkan bahwa sistem pendingin CPU dengan menggunakan Cacade Heat Pipe mampu bekerja optimal dalam memanajemen panas yang dihasilkan oleh processor Central Processing Unit (CPU) komputer. 


\section{UCAPAN TERIMA KASIH}

Terima kasih diucapkan kepada Kementerian Riset Teknologi dan Pendidikan Tinggi dan Lembaga Penelitian dan Pengabdian Kepada Masyarakat Udayana atas dukungan dana melalui skema Hibah Penelitian Terapan Unggulan Perguruan Tinggi (PTUPT) dengan Kontrak Nomor 171.123/UN14.4.A/LT/2018, serta kepada Laboratorium AHTRG FT UI atas dukungan peralatan data aquisisi.

\section{DAFTAR PUSTAKA}

[1] J. A. Ranga Babu, K. K. Kumar, and S. Srinivasa Rao, "State-of-art review on hybrid nanofluids," Renew. Sustain. Energy Rev., vol. 77, pp. 551-565, Sep. 2017.

[2] S. Brenner, Law in an era of smart technology. Oxford University Press, 2007.

[3] Q. Chen and Y. Huang, "Scale effects on evaporative heat transfer in carbon nanotube wick in heat pipes," Int. J. Heat Mass Transf., vol. 111, pp. 852-859, 2017.

[4] K. V. Paiva and M. B. H. Mantelli, "Wire-plate and sintered hybrid heat pipes: Model and experiments," Int. J. Therm. Sci., vol. 93, pp. 36-51, 2015.

[5] A. B. Solomon, K. Ramachandran, and B. C. Pillai, "Thermal performance of a heat pipe with nanoparticles coated wick," Appl. Therm. Eng., vol. 36, no. 1, pp. 106-112, 2012.

[6] N. K. Gupta, A. K. Tiwari, and S. K. Ghosh, "Heat transfer mechanisms in heat pipes using nanofluids - A review," Exp. Therm. Fluid Sci., vol. 90, pp. 84-100, 2018.

[7] N. Putra and W. N. Septiadi, Teknologi Pipa Kalor Teori, Desain, dan Aplikasi. Jakarta: Universitas Indonesia, 2014.

[8] L. L. Vasiliev, "Heat pipes in modern heat exchangers," Appl. Therm. Eng., vol. 25, no. 1, pp. 1-19, 2005.

[9] W. N. Septiadi, I. N. Budiarsa, I. A. Tnunay, I. Desy, W. Ainun, and W. Ula, "Sistem Pendingin Central Processing Unit ( CPU ) Berbasis Cascade Straight Heat Pipe,’Prosiding SNTTM XVII, Oktober, hal. 275-281, 2018. 